\title{
Analisis Kualitas Kerja dan Disiplin Pegawai di Kelurahan Tanjung Buntung
}

\author{
Supriyanto $^{1^{*}}$, Shendi Fiani ${ }^{2}$, Desy Puspita ${ }^{3}$, Thasrif Murhadi ${ }^{3}$, Fajri Salimi ${ }^{4}$, Lisnawati ${ }^{4}$, Zahriatul Aini $^{4}$ \\ ${ }^{1}$ Prodi Administrasi Bisnis, Politeknik LP3I Medan, Medan, Indonesia \\ ${ }^{2}$ Prodi Manajemen, Sekolah Tinggi Ilmu Manajemen Sukma, Medan, Indonesia \\ ${ }^{3}$ Prodi Manajemen Keuangan Sektor Publik, Politeknik Kutaraja, Banda Aceh, Indonesia \\ ${ }^{4}$ Program Studi Analisi Keuangan, Politeknik Kutaraja, Banda Aceh, Indonesia \\ Email: ${ }^{1 *}$ faiziqameira@gmail.com, ${ }^{2}$ shendifiani@gmail.com, ${ }^{3}$ desypuspita@poltekkutaraja.ac.id, \\ 4thasrifmurhadi@poltekkutaraja.ac.id, ${ }^{5}$ fajrisalimi@poltekkutaraja.ac.id, ${ }^{6}$ lisnawati@poltekkutaraja.ac.id, \\ 7zahriatulaini@poltekkutaraja.ac.id
}

\begin{abstract}
Abstrak
Kinerja merupakan cara kerja seseorang yang dapat dicapai oleh seorang karyawan dalam melaksanakan tugas sesuai dengan tanggung jawab yang diberikan kepadanya. Tujuan penelitian ini adalah untuk mengetahui apakah ada pengaruh kualitas kerja dan disiplin pegawai terhadap kualitas pelayanan publik di Kelurahan Tanjung Buntung. Sampel penelitian ini adalah 30 orang masyarakat dan 30 orang pegawai kelurahan data yang diambil dari data tahun 2018. Analisis data menggunakan uji Regresi Linier Berganda, pengujian hipotesis menggunakan uji koefisien determinasi (R2), Uji parsial (uji t), dan uji serempak (uji F), sedangkan pengolahan data menggunakan perangkat lunak pengolahan data. Hasil penelitian menunjukkan bahwa disiplin kerja sangat berpengaruh terhadap kualitas pelayanan publik, sedangkan variabel kualitas kerja berpengaruh negatif terhadap kualitas pelayanan publik.
\end{abstract}

Kata Kunci: Kualitas kerja, Disiplin pegawai, Kualitas Pelayanan Publik

\section{PENDAHULUAN}

Penelitian ini dilakukan di Kelurahan Tanjung Buntung Kecamatan Bengkong Kota Batam. Sebagai institusi layanan publik, Kelurahan Tanjung Buntung fokus untuk memberikan pelayanan yang maksimal kepada masyarakat. Pelayanan pada masyarakat diharapkan dapat sesuai dengan harapan stakeholder, sehingga seluruh pegawai diharpakan dapat disiplin dan mampu meningkatkan kualitas layanan. Masyarakat secara keseluruhan berharap diperlakukan sebagai pelanggan serta berharap bahwa terdapat upaya-upaya pengembangan pelayanan. Setiap pegawai harus berupaya untuk membantu, menyiapkan, menyediakan atau mengurus keperluan masyarakat sehingga dapat memberikan sesuatu yang disampaikan dan disajikan.

\section{METODOLOGI PENELITIAN}

\subsection{Kualitas Kinerja}

Kualitas merupakan suatu strategi organisasi untuk memberikan komitmennya pada pada peningkatan kepuasan pelanggan secara berkelanjutan memperbaiki proses organisasional. Kinerja adalah prestasi kerja yang merupakan hasil dari implementasi rencana kerja yang dibuat oleh suatu institusi yang dilaksanakan oleh pimpinan dan karyawan (SDM) yang bekerja [1]. Performance-based management is a systematis approach to performance improvement through an on going process of establishing strategic performance objectives, measuring performance, collecting, analyzing, reviewing, and reporting performance data, an using that data to drive performance improvement [2]. Faktor Faktor yang Mempengaruhi Kualitas Kerja Karyawan

1. Kemampuan dan Keahlian

Merupakan kemampuan atau skill yang dimiliki seseorang dalam melakukan suatu pekerjaan. Semakin memiliki kemapuan dan keahlian makan akan dapat menyelesaikan pekerjaannya secara benar, sesuai dengan yang telah ditetapkan. Artinya karyawan yang memiliki kemampuan dan keahlian yang lebih baik, maka akan memberikan kinerja yang baik pula demikian sebaliknya. Dengan demikian kemampuan dan keahlian akan mempengaruhi kinerja seseorang.

2. Pengetahuan

Maksudnya adalah pengetahuan tentang pekerjaan. Seseorang yang memiliki pengetahuan tentang pekerjaan secara baik akan memberikan hasil pekerjaan yang baik, demikian sebaliknya. Jadi disimpulkan bahwa pengetahuan tentang pekerjaan akan mempengaruhi kinerja.

3. Rancangan kerja

Merupakan rancangan pekerjaan yang akan memudahkan dalam mencapai tujuannya. Artinya jika suatu pekerjaan memiliki rancangan yang baik, makan akan memudahkan untuk menjalankan pekerjaan tersebut secara tepat dan benar. Demikian pula sebaliknya, maka dapat disimpulan bahwan rancangan pekerjaan akan mempengaruhi kinerja seseorang.

4. Kepribadian

Yaitu kepribadian seseorang atau karakter yang dimiliki seseorang. Setiap orang memiliki kepribadian atau karakter yang berbeda satu dengan yang lainnya. Seseorang yang memiliki kepribadian atau karakter yang baik akan dapat melakukan pekerjaan secara sungguh sungguh penuh tanggung jawab sehingga hasil perkerjaan juga baik.

5. Motivasi kerja

Motivasi kerja merupakan dorongan bagi seseorang untuk melakukan pekerjaan. Jika karyawan memiliki dorongan yang kuat dari dalam dirinya atau dorongan dari luar dirinya, maka karyawan akan terdorong untuk melakukan pekerjaan 
dengan baik. Pada akhirnya dorongan baik dari dalam maupun dari luar diri seseorang akan menghasilkan kinerja yang baik.

6. Kepemimpinan

Kepemimpinan merupakan perilaku seseorang dalam mengatur, mengelola dan memerintah bawahannya untuk mengerjakan suatu tugas dan tanggung jawab yang diberikan.

7. Gaya kepepimpinan

Merupakan gaya atau sikap seorang pemimpin dalam menghadapi atau memerintah bawahannya.

8. Kepuasan kerja

Merupakan perasaan senang atau gembira atau perasaan suka seseorang sebelum setelah melakukan suatu pekrerjaan.

Jika karyawan merasa senang atau gembira atau sukan untuk bekerja, maka hasil pekerjaan akan baik pula [3].

Terdapat beberapa indikator dari kualitas kerja sebagai berikut :

1. Potensi diri

2 Hasil kerja optimal

3 Proses kerja

4. Antusiasme [3].

\subsection{Disiplin}

Disiplin kerja diartikan sebagai pelaksanaan manajemen untuk memperteguh pedoman-pedoman organisasi. Namun, perilaku pekerja dalam organisasi menjadi sangat mengganggu sehingga berdampak dengan kinerja yang menurun [4]. Faktor faktor yang mempengaruhi tingkat kedisiplinan karyawan sebagai berikut :

1. Tujuan dan kemampuan

Tujuan dan kemampuan ikut mempengaruhi tingkat kedisiplinan karyawan. Tujuan yang akan dicapai harus jelas dan ditetapkan secara ideal. Hal ini berarti bahwa tujuan atau pekerjaan yang dibebankan kepada karyawan harus sesusai dengan kemampuan karyawan yang bersangkutan, agar karyawan dapat bekerja sungguh-sungguh dan disiplin dalam mengerjakannya.

2. Teladan pimpinan

Teladan pimpinan sangat berperan dalam menentukan kedisiplinan karyawan karena pimpinan dijadikan teladan dan panutan. Para pimpinan harus memberikan contoh yang baik karena dengan pimpinan yang baik maka kedisiplinan karyawan pun akan meningkat.

3. Keadilan

Keadilan yang dijadikan dasar kebijakan dalam pemberian balas jasa atau hukuman akan merangsang terciptanya kedisiplinan karyawan yang baik. Keadilan ikut mendorong terwujudnya kedisiplinan karyawan karena sifat manusia yang selalu merasa dirinya penting dan meminta diberlakukan secara adil dengan manusia yang lain. perilaku yang dilakukan karyawannya. Hal ini berarti atasan harus selalu hadir di tempat kerja agar dapat mengawasi dan memberikan petunjuk kepada karyawan, apabila ada karyawannya yang mengalami kesulitan. Pengawasan melekat merupakan tindakan yang paling efektif dalam mewujudkan kedisiplinan kerja para karyawan dalam perusahaan.

4. Sanksi hukuman

Sanksi hukuman berperan penting dalam memelihara kedisiplinan karyawan. Dengan adanya sanksi hukuman, kemungkinan besar karyawan tidak akan melanggar peraturan- peraturan yang berlaku. Berat atau ringan sanksi yang diberikan dapat mengubah perilaku para karyawan agar tidak mengulangi kesalahan sebelumnya.

5. Ketegasan

Ketegasan pimpinan dalam melakukan tindakan akan mempengaruhi kedisiplinan karyawan. Pimpinan harus berani dan tegas, bertindak untuk memberikan hukuman kepada setiap karyawan yang indisipliner sesuai dengan sanksi hukuman yang telah ditentukan. Pimpinan yang tegas dalam menerapkan hukuman akan disegani dan diakui kepemimpinannya.

6. Hubungan Kemanusian

Hubungan kemanusian yang harmonis di antara pegawai ikut menciptakan kedisiplinan yang baik di suatu perusahaan. Manajer atau pimpinan harus mewujudkan suasana hubungan kemanusiaan yang serasi, vertical maupun horizontal. Hubungan vertical disini yaitu antara karyawan dengan pimpinan. Sedangkan hubungan horizontal yaitu antara sesama karyawan. Jadi, terciptanya hubungan kemanusian yang serasi akan mewujudkan lingkungan dan suasana kerja yang nyaman [3].

Indikator Kedisiplinan, yaitu:

1. Tujuan dan kemampuan

Tujuan dan kemampuan ikut mempengaruhi tingkat kedisiplinan karyawan. Tujuan yang akan di capai harus jelas dan ditetapkan secara ideal serta cukup menantang bagi kemapuan karyawan harus sesuai dengan kemapuan karyawan yang bersangkutan, agar dua bekerja sungguh sungguh dan disiplin dalam mengerjakannya.

2. Teladan kepemimpinan

Teladan pimpinan sangat berperan dalam menentukan kedisiplinan karyawan karena pimpinan dijadikan teladan dan panutan oleh para bawahannya. Pimpinan harus memberikan contoh baik, berdisiplin baik, jujur, adil serta sesuai kata dengan perbuatannya. Dengan teladan pimpinan yang baik, kedisiplinan akan baik. Jika teladan pimpinan kurang baik, para bawahannya pun akan kurang disiplin.

3. Balas jasa 
Balas Jasa (gaji dan kesejahteraan) ikut mempengatuhi kedisiplinan karyawan karena balas jasa akan memberikankeputusan dan kecintaan karyawan terhadap perusahaan/pekerjaan, jika kecintaan karyawan semakin baik terhadap pekerjaan, kedisplinan akan semakin baik.

4. Keadilan

Keadilan ikut mendorong terwujudnya kedisplinan karyawan, karena ego dan sifat manusia yang selali merasa dirinya penting dan minta diperlakukan sama dengan manusia lainnya. Keadilan yang dijadikan dasar kebijaksanaan dalam pemberian balas jasa atau hukuman akan mendorong terciptanya kedisplinan karyawan yang baik.

5. Waskat

Waskat (pengawan melekat) adalah tindakan nyata dan paling efektif dalam mewujudkan kedisiplinan karyawan. Dengan wakat berarti atasan harus aktif dan langsung mengawasi prilaku, moral, sikap, gairah kerja, dan prestasi kerja bawahannya. Hal ini berarti atasan harus selalu ada atau hadir di tempat kerja agar dapat mengawasi dan memberikan petunjuk, jika ada bawannya yang mengalami kesulitan dalam menyelesaikan pekerjaannya.

6. Hubungan kemanusiaan

Hubungan kemanusiaan yang harmonis diantara sesame karyawan ikut menciptakan kedisplinan yang baik pada suatu perusahaan, hubungan bersifat vertical maupun horizontal yang terdiri dari direct single, relationship, direct group relationship, and cross relationship hendaknya harmonis [3].

\subsection{Kualitas Pelayanan}

Pelayanan publik dapat diartikan sebagai pemberian layanan keperluan orang atau masyarakat yang mempunyai kepentingan pada organisasi itu sesuai dengan aturan pokok dan tata cara yang telah ditetapkan. Kepuasan pelanggan akan tercapai bila kualitas pelayanan yang dirasakan oleh pelanggan sama dengan jasa yang diharapkan, dalam arti kesenjangan yang terjadi adalah kecil atau masih dalam batas toleransi [4].

Terdapat beberapa indikator yang mempengaruhi kualitas pelayanan, antara lain :

1. Kecepatan pelayanan

2. Ketepatan waktu

3. Kecepatan respon

4. Keramahan

5. Kenyamanan [2].

\subsection{Metode Analisis Data}

Populasi adalah wilayah generalisasi objek yang mempunyai kualitas dan karakteristik tertentu yang ditetapkan oleh peneliti untuk dipelajari dan kemudian ditarik kesimpulannya. Penentuan populasi merupakan tahapan penting dalam penelitian. Populasi yang diambil dalam penelitian ini adalah pegawai Kelurahan Tanjung Buntung berjumlah 30 orang. Sedangkan populasi yang diambil dari masyarakat, merupakan rata-rata masyarakat yang datang dalam 1 minggu sebanyak 30 oarng. Sampel dari pegawai adalah seluruhpegawai sebanayk 30 orang, sedangkan sampel masyarakat sebanyak 30 orang.

\subsection{Hipotesis}

Hipotesis adalah asumsi atau dugaan mengenai suatu hal yang dibuat untuk menjelaskan suatu hal yang sering dituntut untuk melakukan pengecekannya. Formulasi hipotesis penelitian ini yaitu :

1. Terdapat pengaruh secara serempak Kualitas Kerja dan Disiplin terhadap Kualitas Pelayanan Publik

2. Terdapat pengaruh Kualitas Kerja terhadap Kualitas Pelayanan Publik

3. Terdapat pengaruh Disiplin terhadap Kualitas Pelayanan Publik

\section{ANALISA DAN PEMBAHASAN}

\subsection{Uji Regresi Linier Berganda}

Pengujian dilakukan untuk mengetahui pengaruh kualitas kerja dan disiplin pegawai terhadap kualitas pelayanan publik di Kelurahan Tanjung Buntung. Berikut tabel, hasil pengujian regreasi linier berganda pada masing masing variabel yaitu :

Tabel 1. Hasil Uji Regresi Linier Berganda

\begin{tabular}{|c|c|c|c|c|c|c|}
\hline \multicolumn{7}{|c|}{ Coefficients $^{\mathrm{a}}$} \\
\hline & \multirow[t]{2}{*}{ Model } & \multicolumn{2}{|c|}{$\begin{array}{c}\text { Unstandardized } \\
\text { Coefficients }\end{array}$} & \multirow{2}{*}{$\begin{array}{c}\begin{array}{c}\text { Standardized } \\
\text { Coefficients }\end{array} \\
\text { Beta }\end{array}$} & \multirow[t]{2}{*}{$t$} & \multirow[t]{2}{*}{ Sig. } \\
\hline & & $\mathrm{B}$ & Std. Error & & & \\
\hline \multirow{3}{*}{1} & (Constant) & 14.555 & 5.450 & & 2.671 & .013 \\
\hline & Kualitas Kerja & -.097 & .132 & -.123 & -.733 & .470 \\
\hline & Disiplin & .716 & .166 & .726 & 4.308 & .000 \\
\hline
\end{tabular}

a. Dependent Variable: Pelayanan

Berdasarkan hasil pengujian diatas, maka diperoleh persamaan regresi linier berganda sebagai berikut :

$$
\mathrm{Y}=14.555-0.097 \mathrm{X}_{1}+0.716 \mathrm{X}_{2}+\mathrm{e}
$$


Pada model regresi linier berganda diperoleh nilai konstanta Kualitas Pelayanan Publik sebesar 14.555 artinya nilai variabel bebas Kualitas Kerja dan Disiplin nilainya 0, maka variabel Kualitas Pelayanan Publik nilainya sebesar 14.555. Koefisien regresi variabel bebas Kualitas Kerja bernilai negatif, artinya bahwa Kualitas Pelayanan Publik dipengaruhi secara negatif oleh Kualitas Kerja Pegawa, sedangkan variabel Disiplin Kerja bernilai positif, artinya Kualitas Pelayanan Publik dipengaruhi secara positif oleh Disiplin Kerja.

\subsection{Penguji Hipotesis}

a. Koefisien Determinasi $\left(\mathbf{R}^{2}\right)$

Koefesien determinasi bertujuan untuk mengukur berapa besar kemampuan variabel bebas dalam menerangkan variabel terikat. Nilai koefisien determinasi dapat dilihat pada tabel berikut :

Tabel 2. Hasil Uji Koefisien Determinasi $\left(\mathrm{R}^{2}\right)$

Model Summary

\begin{tabular}{ccccc}
\hline Model & R & R Square & Adjusted R Square & Std. Error of the Estimate \\
\hline 1 & $.669^{\mathrm{a}}$ & .447 & .406 & 3.204 \\
\hline
\end{tabular}

a. Predictors: (Constant), Disiplin, Kualitas

Nilai koefisien determinasi yang diperoleh sebesar 0.669 atau 66.9\% menunjukkan bahwa Variabel Kualitas Kerja dan Displin Pegawai mampu menjelaskan variasi yang terjadi pada Variabel Kualitas Pelayanan Publik., sedangkan sisanya $33.1 \%$ dijelaskan oleh variabel lain yang tidak diteliti dalam penelitian ini antara lain motivasi, budaya organisasi, kepemimpinan, kompetensi pegawai dll.

\section{b. Uji Serempak (Uji F)}

Uji serempak dilakukan untuk mengetahui pengaruh kualitas kinerja dan disiplin pegawai secara simultan terhadap kualitas pelayanan publik, penguji dilakukan pada tingkat kepercayaan 95\% atau tingkat kesalahan $\alpha=0.05(5 \%)$

Table 3. Hasil Uji Serempak (Uji F)

\begin{tabular}{|c|c|c|c|c|c|}
\hline \multicolumn{6}{|c|}{ ANOVA $^{\mathbf{a}}$} \\
\hline Model & $\begin{array}{c}\text { Sum of } \\
\text { Squares }\end{array}$ & df & $\begin{array}{l}\text { Mean } \\
\text { Square }\end{array}$ & $\mathrm{F}$ & Sig. \\
\hline Regression & 224.354 & 2 & 112.177 & 10.930 & $.000^{\mathrm{b}}$ \\
\hline 1 Residual & 277.113 & 27 & 10.263 & & \\
\hline Total & 501.467 & 29 & & & \\
\hline
\end{tabular}

a. Dependent Variable: Pelayanan

b. Predictors: (Constant), Disiplin, Kualitas

Berdasarkan tabel 3, diketahui bahwa nilai $\mathrm{F}_{\text {hitung }}$ yaitu $10.930>$ nilai $\mathrm{F}_{\text {tabel }}$ yaitu 3.35 dan nilai signifikan $0.000<$ dari nilai alpha 0.05 . Maka dapat diketahui bahwa kualitas kerja $\left(\mathrm{X}_{1}\right)$ dan displin pegawai $\left(\mathrm{X}_{2}\right)$, secara simultan berpengaruh positif dan signifikan terhadap kualitas pelayanan publik.

\section{c. Uji Parsial (Uji t)}

Uji parsial (uji t) bertujuan untuk melihat pengaruh secara parsial, baik kualitas kerja maupun disiplin pegawai terhadap kualitas pelayanan publik.

Tabel 4. Hasil Uji Parsial

$$
\text { Coefficients }^{\text {a }}
$$

\begin{tabular}{llccccc}
\hline \multirow{2}{*}{ Model } & \multicolumn{2}{c}{$\begin{array}{c}\text { Unstandardized } \\
\text { Coefficients }\end{array}$} & $\begin{array}{c}\text { Standardized } \\
\text { Coefficients }\end{array}$ & \multirow{2}{*}{$\mathrm{t}$} & \multirow{2}{*}{ Sig. } \\
\cline { 3 - 5 } & \multicolumn{2}{c}{$\mathrm{B}$} & Std. Error & Beta & & \\
\hline \multirow{4}{*}{1} & (Constant) & 14.555 & 5.450 & & 2.671 & .013 \\
& Kualitas Kerja & -.097 & .132 & -.123 & -.733 & .470 \\
& Disiplin & .716 & .166 & .726 & 4.308 & .000 \\
\hline
\end{tabular}

a. Dependent Variable: Pelayanan

1. Nilai $t_{\text {hitung }}$ untuk variabel kualitas kerja $(-0.733)<$ ttabel 2.051 dan nilai sig $0.470>$ dari alpha 0.05 , secara parsial variabel kualitas kerja tidak berpengaruh terhadap kualitas pelayanan publik.

2. Nilai $t_{\text {hitung }}$ untuk variabel displin $4.308>\mathrm{t}_{\text {tabel }} 2.051$ dan nilai sig $0.000<$ dari nilai alpha $(0.05)$, maka secara parsial variabel disiplin pegawai berpengaruh positif terhadap kualitas pelayanan publik. 


\section{KESIMPULAN}

Berdasarkan pembahasan maka dapat disimpulkan maka dapat disimpulkan bahwa secara serempak, kualitas kerja dan disiplin pegawai berpengaruh positif dan signifikan terhadap kualitas pelayanan publik. Sedangkan secara parsial variabel kualitas kerja tidak berpengaruh terhadap kualitas pelayanan publik, sementara disiplin berpengaruh positif dan signifikan terhadap kualitas pelayanan publik

\section{REFERENCES}

[1] Wibowo. (2013). Manajemen Kinerja (7th ed.). Jakrta: PT. Raja Grafindo Persada

[2] Mahmudi. (2015). Manajemen Kinerja Sektor Publik (3rd ed.). YOGYAKARTA: SEKOLAH TINGGI ILMU MANAJEMEN YKPN.

[3] Hasibuan, S. P. Malayu,(2013), Manajemen Sumber Daya Manusia. Edisi Revisi. Jakarta: Penerbit PT. Bumi Aksara.

[4] Mangkunegara, P. Anwar. 2011. Manajemen Sumber Daya Manusia Perusahaan. Cetakan kesepuluh. PT. REMAJA ROSDAKARYA. Bandung.

[5] Hayat. (2017). Manajemen Pelayanan Publik (2nd ed.). Depok: PT. Raja Grafindo Persada.

[6] Sugiyono. (2018). Metode Penelitian Manajemen. (Setiyawami, Ed.) (6th ed.). BANDUNG: ALFABETA, CV BANDUNG. 